\title{
Remediation of Rhodamine B Dye from Aqueous Solution Using Casuarina equisetifolia Cone Powder as a Low-Cost Adsorbent
}

\author{
Muhammad Khairud Dahri, Muhammad Raziq Rahimi Kooh, and Linda B. L. Lim \\ Faculty of Science, Universiti Brunei Darussalam, Jalan Tungku Link, Pengkalan Gadong, \\ Bandar Seri Begawan BE1410, Brunei Darussalam \\ Correspondence should be addressed to Muhammad Raziq Rahimi Kooh; chernyuan@hotmail.com
}

Received 28 July 2016; Accepted 22 September 2016

Academic Editor: Leonardo Palmisano

Copyright (C) 2016 Muhammad Khairud Dahri et al. This is an open access article distributed under the Creative Commons Attribution License, which permits unrestricted use, distribution, and reproduction in any medium, provided the original work is properly cited.

\begin{abstract}
The removal of toxic dye rhodamine B (RB) from aqueous solution was achieved by using Casuarina equisetifolia cone (CEC) as an adsorbent. Batch experiment method was used in order to investigate the effects of contact time, $\mathrm{pH}$, temperature, ionic strength, and dye concentration on the adsorption process. Kinetics and isotherm theoretical models were applied on the experimental data and it was found that the pseudo-2nd-order kinetics and the Langmuir isotherm model best fitted into the data. The Langmuir maximum adsorption capacity for CEC was determined as $49.5 \mathrm{mg} \mathrm{g}^{-1}$. The adsorption of RB onto CEC is thermodynamically favourable, feasible, and endothermic in nature.
\end{abstract}

\section{Introduction}

The use of synthetic colouring agents in textile, paper, leather, and plastic industries leads to the growing concern of the dye wastewater. Many synthetic dyes are chemically and thermally stable and are usually nonbiodegradable. Dye wastewater must be treated before discharge to the environment. However, such practices of direct discharge of dye wastewater were being observed in some low-income countries, and the damage is not limited to ecological damage, but also to the health of those who consume the water [1].

There are many methods available for treating dye wastewater such as ozonation, addition of reducing agents, Fenton's method, membrane filtration, ion-exchange, and adsorption methods where their advantages and disadvantages are widely discussed in literature [2]. Among these methods, adsorption is one of the simplest and most researched methods in the last decade [3]. Adsorption is also widely used for the removal of pollutants that are not easily biodegradable [2]. The cost of dye wastewater remediation by adsorption depends on the removal efficiency of the adsorbent as well as its sources. Low-cost adsorbents may include materials that can be found in abundance such as weeds or agricultural wastes, while higher-cost adsorbents may include chemically treated materials.

Casuarina equisetifolia is a multipurpose crop native in Australia, Bangladesh, Brunei Darussalam, Malaysia, Thailand, and Philippines islands [4] which was introduced to India, China, Egypt, Tanzania, and North America for agroforestry research [5]. This plant is a nonleguminous plant and capable of forming symbiosis relationship with phosphate mobilising mycorrhizae for its phosphate's need, while the nitrogen source can be obtained through nitrogen-fixing Frankia in root nodules [5], thereby reducing the need of inputs.

In this study, the Casuarina equisetifolia cone (CEC) was investigated as a potential adsorbent for the removal of rhodamine $B(\mathrm{RB})$. In our previous studies, we reported the potential of Casuarina equisetifolia needle (CEN) as a good adsorbent for the removal of RB [6], methyl violet [7], and malachite green [8]. CEC contributes to $2-10 \%$ of total plant litter from a Casuarina equisetifolia tree [9]. CEC has no economic importance and is not used for landscape purposes, unlike the CEN. The nutrient density of CEC is lower than CEN [10], while upon decomposition the CEC releases less nitrogen than CEN which makes CEC a less useful material 
for composting or as biofertiliser [9]. Another reason of using CEC as an adsorbent is because of the brittleness feature which allows the biomass to be easily processed into powder. CEC also contain lignocellulosic material which is one of the known materials used for remediation of pollutants [11]. Currently, there are no reports on the use of CEC as an adsorbent for removal of dyes; however, the cones of Pinus radiata tree, unrelated to Casuarina species, were reported to be used for removal of methylene blue [12] and congo red [13].

The xanthine dye, $\mathrm{RB}$, is chosen for this study because of its importance in paint, textile, and paper industries [14]. $\mathrm{RB}$ was reported to cause mutagenic effect and reproductive toxicity in rats [15] and is also toxic to fish with a $\mathrm{LC}_{50}$ of $83.9 \mathrm{mg} \mathrm{L}^{-1}$ reported for Cyprinodon variegatus [16].

\section{Materials and Methods}

2.1. Preparation of Adsorbent and Adsorbate. Casuarina equisetifolia cone (CEC) was collected from the campus ground and was washed using water before drying it in the oven at $70^{\circ} \mathrm{C}$ for few days. The dried CEC was then blended and sieved to obtain particle size of $355 \mu \mathrm{m}$. The sample was kept in sealed plastic bag until further use.

Rhodamine B (RB) $\left(\mathrm{C}_{28} \mathrm{H}_{31} \mathrm{ClN}_{2} \mathrm{O}_{3}, M_{r} 479.01 \mathrm{~g} \mathrm{~mol}^{-1}\right)$, with purity of $95 \%$ dye content, was purchased from SigmaAldrich. RB stock solution $\left(1000 \mathrm{mg} \mathrm{L}^{-1}\right)$ was prepared by dissolving an appropriate amount of $\mathrm{RB}$ in water and a serial dilution was used in order to prepare lower RB concentrations from the stock solution. All reagents were used without further purification and distilled water was used throughout the experiments.

2.2. Characterisation of CEC. The point of zero charge $\left(\mathrm{pH}_{\mathrm{pzc}}\right)$ of CEC was determined using the salt addition method [17]. Five solutions of $0.1 \mathrm{~mol} \mathrm{~L}^{-1} \mathrm{KNO}_{3}(20 \mathrm{~mL})$ were prepared and the $\mathrm{pH}$ of each solution was adjusted to $\mathrm{pH} 2,4$, 6,8 , and 10 using $0.1 \mathrm{~mol} \mathrm{~L}^{-1} \mathrm{NaOH}$ and $\mathrm{HNO}_{3} .0 .04 \mathrm{~g}$ of CEC was mixed with the salt solutions in conical flasks and the mixtures were agitated using Stuart Orbital Shaker at a speed of $250 \mathrm{rpm}$ for $24 \mathrm{~h}$. The $\mathrm{pH}$ of the solutions was measured using a Thermo-Scientific digital $\mathrm{pH}$ meter after the $24 \mathrm{~h}$ agitation. The $\mathrm{pH}_{\mathrm{pzc}}$ was determined from the plot of $\Delta \mathrm{pH}$ (final $\mathrm{pH}-$ initial $\mathrm{pH}$ ) versus initial $\mathrm{pH}$.

The identification of CEC and CEC-RB's functional groups was done by Fourier transform infrared (FTIR) spectroscopy (Shimadzu Model IR Prestige-21 spectrophotometer) using the $\mathrm{KBr}$ disc method. The $\mathrm{KBr}$ was purchased from Sigma-Aldrich and of spectroscopy grade. It was dried at $110^{\circ} \mathrm{C}$ for $2 \mathrm{~h}$ prior to the analysis in order to remove the moisture.

The surface morphology of the samples was done using scanning electron microscope (SEM) (Tescan Vega XMU). The samples were placed on carbon tape and were gold coated using SPI-MODULE ${ }^{\text {TM }}$ Sputter Coater at plasma current of 8 $\mathrm{mA}$ for 60 seconds.

2.3. Experimental Procedures. Batch experiment used in this study was generally carried out by mixing CEC $(0.05 \mathrm{~g})$ with
$\mathrm{RB}$ solution $(20 \mathrm{~mL})$ of specific concentration in conical flasks and agitated at $250 \mathrm{rpm}$ for a certain period of time. The quantity of the dye after agitation was analysed using UV-visible spectrophotometer (Shimadzu UV-1601PC) at wavelength of $555 \mathrm{~nm}$.

In this study, parameters such as contact time (5-240 $\mathrm{min})$, temperature $\left(25-55^{\circ} \mathrm{C}\right)$, dosage $(0.01-0.06 \mathrm{~g})$, ionic strength (0.1-0.8 $\left.\mathrm{M} \mathrm{KNO}_{3}\right)$, and $\mathrm{pH}(2-10)$ were carried out in order to investigate their effects on the adsorption of $\mathrm{RB}$ onto CEC. The amount of RB adsorbed per gram of CEC and percentage removal are determined by the following equations, respectively:

$$
\begin{aligned}
& \text { Adsorption capacity, } q_{e}\left(\mathrm{mgg}^{-1}\right)=\frac{\left(C_{i}-C_{e}\right) V}{m}, \\
& \text { Percentage removal }=\frac{\left(C_{i}-C_{e}\right) \times 100 \%}{C_{i}},
\end{aligned}
$$

where $C_{i}$ is the initial dye concentration $\left(\mathrm{mg} \mathrm{L}^{-1}\right), C_{e}$ is the dye concentration after agitation $\left(\mathrm{mg} \mathrm{L}^{-1}\right), V$ is the volume of dye solution used (L), and $m$ is the mass of adsorbent used (g).

2.4. Error Analyses. In order to determine the best-fitting model for describing the experimental data in kinetics and isotherm studies, two error functions were used, namely, the sum of absolute error (EABS) and chi-square test $\left(\chi^{2}\right)$. Error functions are useful as the conversion of nonlinear equations into linear forms can violate the error variance of the standard least squares [18, 19]; therefore, determining the best-fitting model based on the value of the coefficient of determination $\left(R^{2}\right)$ alone is inadequate. The lower the value of the error functions, the closer the agreement between the calculated and experimental values and, hence, the better the fitting of the model into the experimental data [20]. The equations of the two error functions are as follows:

$$
\begin{gathered}
\text { Sum of absolute error (EABS): } \sum_{i=1}^{n}\left|q_{e, \exp }-q_{e, \text { cal }}\right| \\
\text { Chi-square test }\left(\chi^{2}\right): \sum_{i=1}^{n} \frac{\left(q_{e, \exp }-q_{e, \mathrm{cal}}\right)^{2}}{q_{e, \exp }}
\end{gathered}
$$

where $q_{e \text { exp }}$ is $q_{e}$ value obtained from the experiment while $q_{e, \text { cal }}$ is the calculated value from the theoretical models and $n$ is the number of data points in the experiment.

2.5. Regeneration Study. The regeneration study on CEC's adsorption capacity after the treatment with $\mathrm{RB}$ dye was done by washing the spent $\mathrm{CEC}$ with water and $0.1 \mathrm{M} \mathrm{NaOH}$ as regenerating solutions. Full details of the regeneration experimental procedures are available in our previous study [21]. Briefly, the spent CEC was made by agitating with $50 \mathrm{mg} \mathrm{L}^{-1}$ $\mathrm{RB}$ and distilled water was used for washing the dye on the adsorbent several times at $30 \mathrm{~min}$ interval. Spent CEC using base treatment was prepared by agitating the spent CEC with $0.1 \mathrm{M} \mathrm{NaOH}$ for $30 \mathrm{~min}$, followed by repeated distilled 


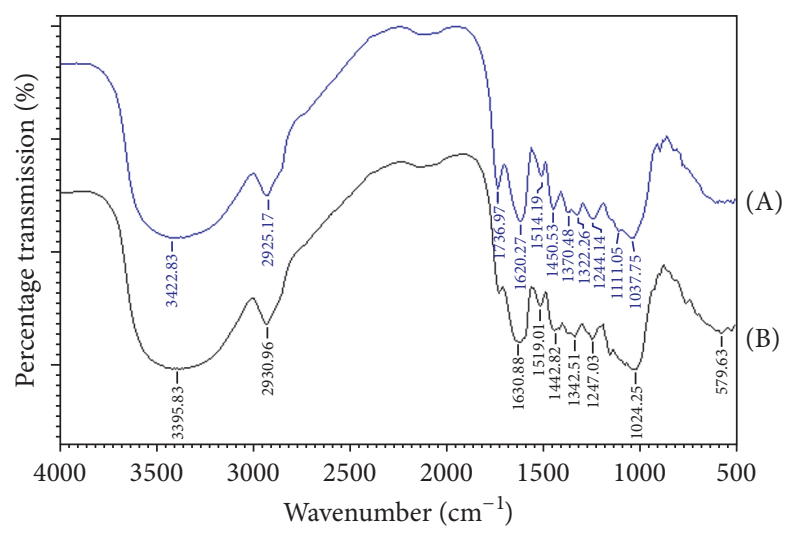

Figure 1: The FTIR spectra for (A) untreated CEC and (B) CEC-RB.

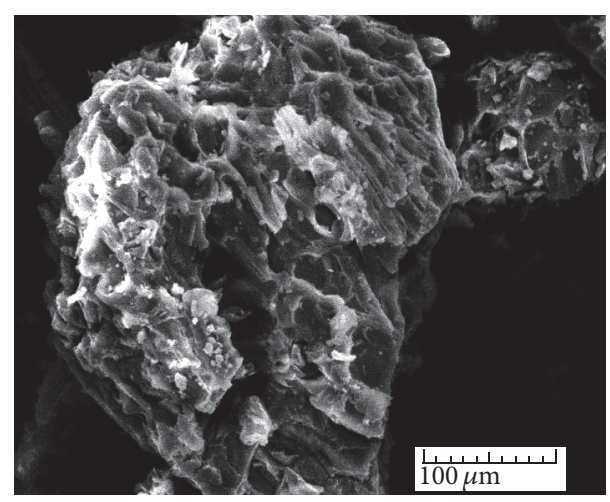

FIGURE 2: SEM image of CEC at 400x magnification.

water washing until the washed solution is near neutral. The regenerated CEC was dried in an oven at $70^{\circ} \mathrm{C}$ overnight before being subjected to fresh $50 \mathrm{mg} \mathrm{L}^{-1} \mathrm{RB}$. This is considered as one cycle and the experiment was carried out until the third cycle.

\section{Results and Discussions}

3.1. Characterisation of CEC. The functional groups identification of CEC and CEC-RB using FTIR is shown in Figures $1(\mathrm{~A})$ and $1(\mathrm{~B})$, respectively. In CEC's FTIR spectrum, $\mathrm{OH}$ and/ or $\mathrm{NH}$ group $\left(3422 \mathrm{~cm}^{-1}\right), \mathrm{CH}\left(2925 \mathrm{~cm}^{-1}\right)$, amide, $\mathrm{NH}_{2}$ bending $\left(1620 \mathrm{~cm}^{-1}\right), \mathrm{CN}$ stretching $\left(1514 \mathrm{~cm}^{-1}\right)$, and $\mathrm{C}-\mathrm{O}$ stretching vibration $\left(1037 \mathrm{~cm}^{-1}\right)$ were observed. In CEC-RB, however, these bands were shifted to $3395,2930,1630,1519$, and $1024 \mathrm{~cm}^{-1}$, respectively, suggesting that these functional groups could be involved in the interaction between CEC's surface and RB molecules. The surface morphology of CEC is displayed in Figure 2 and it can be seen that CEC has rough and irregular surface which suggests large surface area for the adsorption to occur.

The $\mathrm{pH}_{\mathrm{pzc}}$ of $\mathrm{CEC}$ is determined as 4.22. According to the concept of point of zero charge, this value indicates the $\mathrm{pH}$ at which CEC's surface is neutral. When CEC is subjected to higher $\mathrm{pH}$, the surface would be predominately negative in charge due to the deprotonation of its functional group such as carboxyl group. While, in lower $\mathrm{pH}$, the surface is predominately negative in charge due to the protonation of functional group such as amine group. This parameter is useful in the prediction at which $\mathrm{pH}$ the adsorbents can effectively adsorb the adsorbate in solutions.

3.2. Effect of Contact Time and Kinetics Study. The amount of time required for the adsorption process to be in equilibrium can vary depending on the chemical and physical nature of the adsorbent as well as the adsorbate. Therefore, it is useful to investigate the effect of contact time in order to obtain the optimal time to be used for the rest of the experiments. The adsorption of 50,100 , and $200 \mathrm{mg} \mathrm{L}^{-1} \mathrm{RB}$ onto CEC is shown in Figure 3(a) where a rapid increase in $q_{e}$ values in the first $30 \mathrm{~min}$ of contact time was observed and this could be due to the availability of CEC's active sites. Beyond $60 \mathrm{~min}$, the adsorption slowed down which was contributed by the diminishing number of active sites for $\mathrm{RB}$ molecules to interact with.

In this study, the Lagergren 1st-order [22] and pseudo2nd-order [23] models were used to describe the adsorption mechanism while Weber-Morris intraparticle diffusion model [24] was used to investigate the diffusion mechanism of the adsorption process. The linear equations for these models are expressed as follows:

Lagergren 1st-order: $\log \left(q_{e}-q_{t}\right)$

$$
=\log q_{e, \mathrm{cal}}-\frac{t}{2.303} k_{1},
$$

Pseudo-2nd-order: $\frac{t}{q_{t}}=\frac{1}{q_{e, \mathrm{cal}}^{2} k_{2}}+\frac{t}{q_{e, \mathrm{cal}}}$,

Weber-Morris intraparticle diffusion: $q_{t}$

$$
=k_{3} t^{1 / 2}+C \text {, }
$$

where $q_{t}$ is the adsorption capacity at given time $\left(\mathrm{mg} \mathrm{g}^{-1}\right), t$ is the time $(\mathrm{min}), q_{e, \mathrm{cal}}$ is the calculated adsorption capacity $\left(\mathrm{mgg}^{-1}\right)$, and $C$ is the intercept. $k_{1}\left(\mathrm{~min}^{-1}\right), k_{2}$ $\left(\mathrm{g} \mathrm{mg}^{-1} \mathrm{~min}^{-1}\right)$, and $k_{3}\left(\mathrm{mg} \mathrm{g}^{-1} \mathrm{~min}^{-1 / 2}\right)$ are rate constants for the Lagergren 1st-order, pseudo-2nd-order, and WeberMorris intraparticle diffusion model, respectively.

Table 1 summarises the kinetics parameters calculated from each of the models' linear plots. It can be seen that the pseudo-2nd-order has higher coefficient of determination $\left(R^{2}\right)$ values compared to the Lagergren 1st-order. This indicates that the pseudo-2nd-order is more suitable in describing the experimental data than the Lagergren 1st-order model. This is supported by the smaller EABS and $\chi^{2}$ values for pseudo-2nd-order as well as the close agreement of the model's $q_{e, \text { cal }}$ with that of the experimental $q_{e}$. In the WeberMorris model, a straight plot passing through the origin indicates that intraparticle diffusion model is the rate limiting step. In some cases, multilinear plots are also obtained where, in such plots, there are usually three distinct regions that can be seen which represent the film diffusion (1st region), intraparticle diffusion (2nd region), and equilibrium phase 


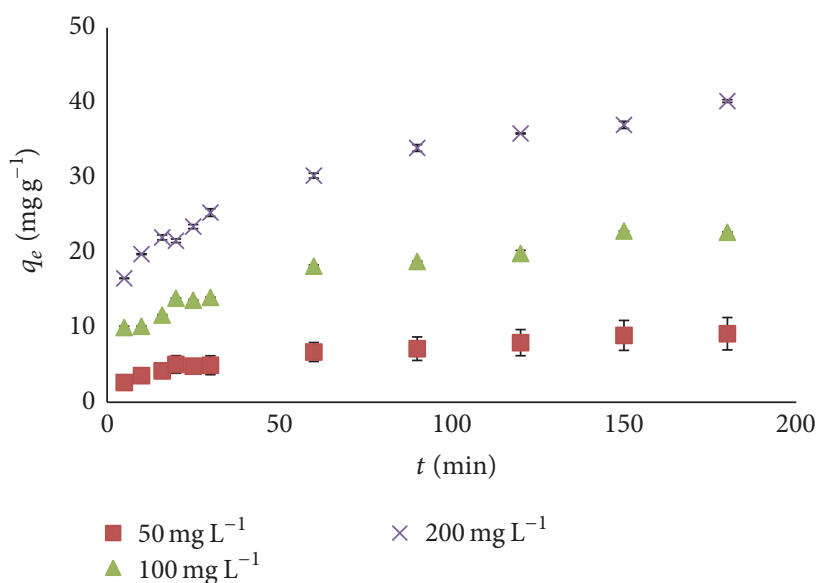

(a)

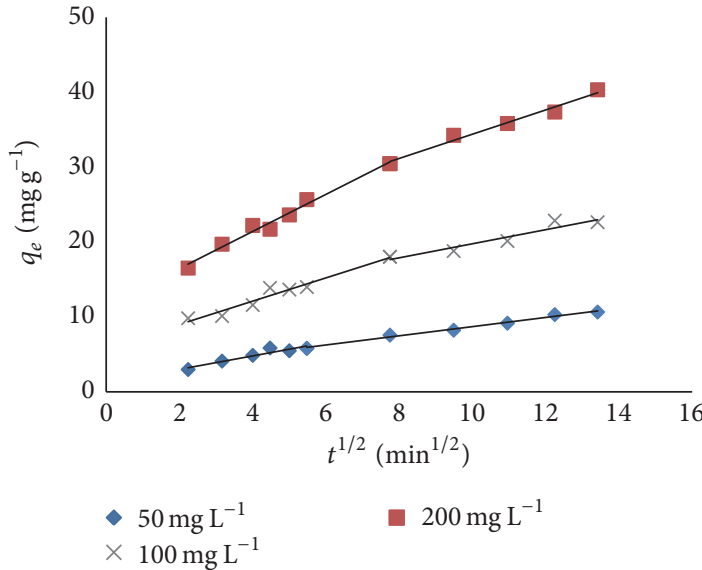

(b)

Figure 3: (a) Effect of contact time on the adsorption at dye concentrations of 50, 100, and $200 \mathrm{mg} \mathrm{L}^{-1} \mathrm{RB}$ onto $0.04 \mathrm{~g}$ CEC and (b) WeberMorris intraparticle diffusion plots.

TABLE 1: The calculated parameters of the kinetics models.

\begin{tabular}{lccc}
\hline$C_{i}\left(\mathrm{mg} \mathrm{L}^{-1}\right)$ & 50 & 100 & 200 \\
\hline \multicolumn{3}{c}{ Lagergren 1st-order model } \\
$q_{e, \text { cal }}\left(\mathrm{mg} \mathrm{g}^{-1}\right)$ & 8.226 & 16.484 & 23.608 \\
$q_{e, \text { exp }}\left(\mathrm{mg} \mathrm{g}^{-1}\right)$ & 10.667 & 22.863 & 40.329 \\
$k_{1}$ & 0.018 & 0.021 & 0.014 \\
$R^{2}$ & 0.919 & 0.918 & 0.995 \\
$\chi^{2}$ & 11.646 & 34.150 & 109.759 \\
EABS & 24.912 & 66.826 & 166.513 \\
\hline & \multicolumn{3}{c}{ Pseudo-2nd-order model } \\
$q_{e, \text { cal }}\left(\mathrm{mg} \mathrm{g}^{-1}\right)$ & 11.560 & 24.245 & 41.938 \\
$q_{e, \text { exp }}\left(\mathrm{mg} \mathrm{g}^{-1}\right)$ & 10.667 & 22.863 & 40.329 \\
$k_{2}$ & 0.004 & 0.002 & 0.001 \\
$R^{2}$ & 0.985 & 0.990 & 0.993 \\
$\chi^{2}$ & 7.182 & 14.619 & 24.406 \\
EABS & 18.614 & 42.424 & 72.061 \\
\hline & Weber-Morris intraparticle diffusion model \\
$k_{3}$ & 0.895 & 1.555 & 2.477 \\
$C$ & 1.234 & 5.896 & 11.493 \\
$R^{2}$ & 0.906 & 0.954 & 0.981 \\
\hline
\end{tabular}

(3rd region) [25]. However, since film diffusion is a very fast process, it is usually not seen in many cases. In this study, multilinear Weber-Morris plots were obtained for all three concentrations (Figure 3(b)). From Table 2, it can be said that the $y$-intercept of each plot did not pass through the origin and thus intraparticle diffusion is not the rate limiting step.

3.3. Effect of pH and Ionic Strength. The condition of dyeing processes varies depending on the nature of the dye; that is, acid dyes work best in acidic condition and reactive dyes need the addition of salt. As the dyeing process does not use up all the dyes in the bath, they are often disposed and if not
TABLE 2: Thermodynamics parameters for the adsorption of RB onto CEC.

\begin{tabular}{lcccc}
\hline $\begin{array}{l}\text { Temperature } \\
\left({ }^{\circ} \mathrm{C}\right)\end{array}$ & $\begin{array}{c}\Delta G^{\circ} \\
\left(\mathrm{kJ} \mathrm{mol}^{-1}\right)\end{array}$ & $\begin{array}{c}\Delta H^{\circ} \\
\left(\mathrm{kJ} \mathrm{mol}^{-1}\right)\end{array}$ & $\begin{array}{c}\Delta S^{\circ} \\
\left(\mathrm{J} \mathrm{mol}^{-1} \mathrm{~K}^{-1}\right)\end{array}$ & $q_{e}\left(\mathrm{mg} \mathrm{g}^{-1}\right)$ \\
\hline 25 & -1.19 & & & 12.08 \\
35 & -1.47 & 14.19 & 51.16 & 12.77 \\
45 & -2.47 & & & 14.09 \\
55 & -2.84 & & & 14.85 \\
\hline
\end{tabular}

properly processed can affect the ecology of the water bodies. $\mathrm{pH}$ and presence of salt can affect the adsorption capacity of an adsorbent and thus it is important to investigate these parameters.

Figure 4(a) shows the effect of $\mathrm{pH}$ on the adsorption of $50 \mathrm{mg} \mathrm{L}^{-1} \mathrm{RB}$ onto $\mathrm{CEC}$. The highest removal was obtained at $\mathrm{pH} 2(75 \%)$ while the other $\mathrm{pH}$ including the ambient $\mathrm{pH}$ yielded similar removal of around $66 \%$. RB dye molecule exists in cationic form when $\mathrm{pH}<4$ [26] and using the concept of $\mathrm{pH}_{\mathrm{pzc}}$ the adsorption of $\mathrm{RB}$ molecules is less favourable in such low $\mathrm{pH}$ due to electrostatic repulsion. However, this was not observed in this study which may be due to the possibility of other forces such as hydrogen bonding and hydrophobic interactions playing bigger roles than electrostatic interaction. Similar observation was reported in the removal of RB using Azolla pinnata [27].

The effect of ionic strength on the adsorption of $50 \mathrm{mg} \mathrm{L}^{-1}$ $\mathrm{RB}$ onto CEC is shown in Figure 4(b). It can be seen that the removal of $\mathrm{RB}$ only decreased when $0.04 \mathrm{M} \mathrm{NaCl}$ and beyond were introduced into the system. The removal of $\mathrm{RB}$ was initially $70 \%$ which decreased to $61 \%$ in $0.8 \mathrm{M} \mathrm{NaCl}$ solution. The reduction of removal capacity is contributed by the competition between the dye molecules and $\mathrm{Na}^{+}$ions for CEC's active sites. Also, the adsorbed $\mathrm{Na}^{+}$can cause electrostatic repulsion due to increase in positive charge on the CEC's surface. However, the reduction was not severe as the 


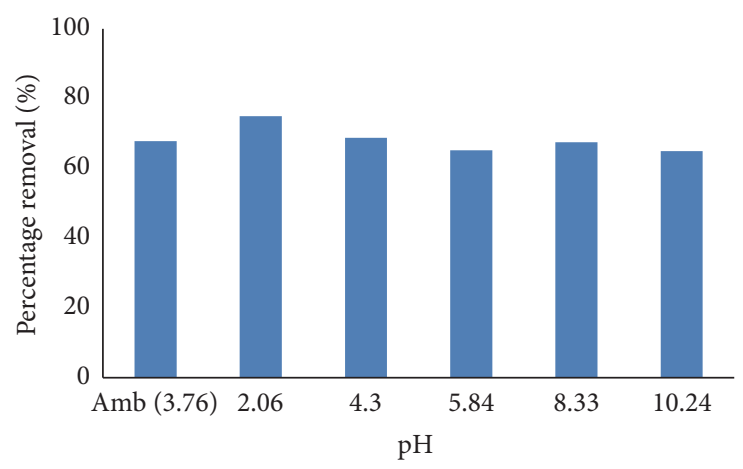

(a)

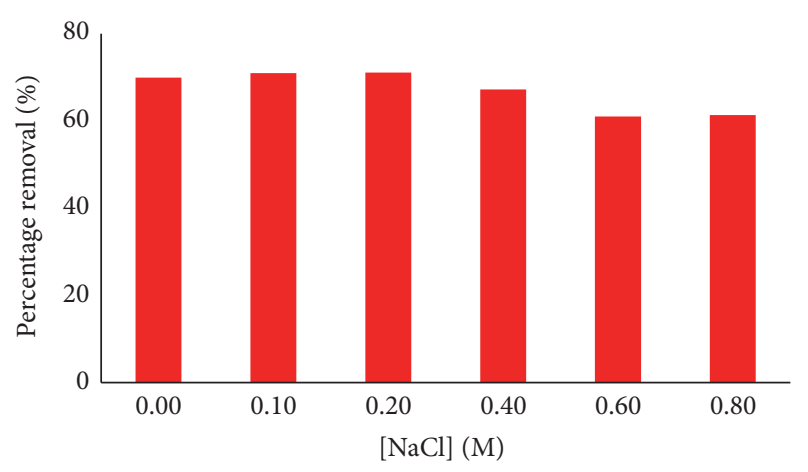

(b)

Figure 4: The effect of (a) $\mathrm{pH}$ and (b) ionic strength on the adsorption of $20 \mathrm{~mL}$ of $50 \mathrm{mg} \mathrm{L}^{-1} \mathrm{RB}$ onto CEC using $0.04 \mathrm{~g}$ adsorbent at agitation speed of $250 \mathrm{rpm}$.

RB molecule is likely to interact with CEC using hydrophobic interaction and hydrogen bonding as mentioned above. Removal of RB using jackfruit seed reported a similar observation [28].

3.4. Effect of Temperature and Thermodynamics Study. Table 2 shows $q_{e}$ values at various temperature as well as the calculated $\Delta S^{\circ}$ and $\Delta H^{\circ}$ values obtained from linear plot presented by (9) and these two parameters are used to calculate $\Delta G^{\circ}$ using (5). It can be seen that increasing the temperature from $25^{\circ} \mathrm{C}$ to $55^{\circ} \mathrm{C}$ only increased $q_{e}$ values by two units which indicates that temperature has little effect on the adsorption process. Thermodynamically, the adsorption in this study is viewed as endothermic due to the increase in $q_{e}$ values and the positive value of $\Delta H^{\circ}$. The negative values of $\Delta G^{\circ}$ indicate the spontaneous reaction while positive $\Delta S^{\circ}$ value showed that the reaction is favourable.

Van 't Hoff equation can be expressed as follows:

$$
\begin{aligned}
\Delta G^{\circ} & =\Delta H^{\circ}-T \Delta S^{\circ}, \\
\Delta G^{\circ} & =-R T \ln k, \\
k & =\frac{C_{s}}{C_{e}}, \\
C_{s} & =C_{i}-C_{e} .
\end{aligned}
$$

By substituting (5) into (6),

$$
\ln k=\frac{\Delta S^{\circ}}{R}-\frac{\Delta H^{\circ}}{R T}
$$

where $T$ is the temperature in Kelvin (K), $\Delta G^{\circ}$ is Gibbs' free energy, $\Delta S^{\circ}$ is the change in entropy, $\Delta H^{\circ}$ is the change in enthalpy, $k$ is the distribution coefficient for adsorption, $C_{s}$ is the amount of $\mathrm{RB}$ adsorbed by the adsorbent after equilibrium $\left(\mathrm{mg} \mathrm{L}^{-1}\right)$, and $R$ is the gas constant $\left(8.314 \mathrm{~J} \mathrm{~mol}^{-1} \mathrm{~K}^{-1}\right)$.

$\Delta S^{\circ}$ and $\Delta H^{\circ}$ were calculated from the linear plot of $\ln k$ versus $1 / T$.

3.5. Effect of Concentration and Isotherm Modelling. As seen in Figure $5, q_{e}$ value increases as the concentration of

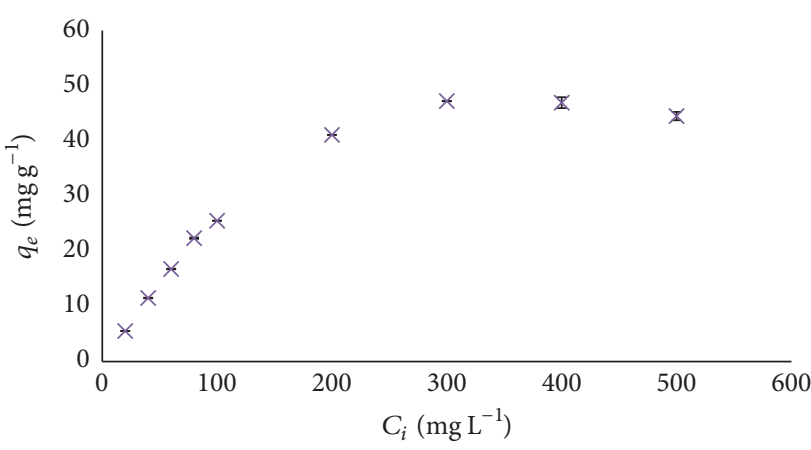

FIGURE 5: The effect of various concentration of RB on the adsorption process $(0.04 \mathrm{~g}$ adsorbent, unadjusted $\mathrm{pH})$.

$\mathrm{RB}$ increased from $20 \mathrm{mg} \mathrm{L}^{-1}\left(5.5 \mathrm{mg} \mathrm{g}^{-1}\right)$ to $200 \mathrm{mg} \mathrm{L}^{-1}$ $\left(41.1 \mathrm{mg} \mathrm{g}^{-1}\right)$. This is contributed by the driving force provided by the concentration gradient which forces more molecules to be transferred from the bulk solution to the adsorbent [29]. Beyond $200 \mathrm{mg} \mathrm{L}^{-1}$, the adsorption slowed down to a point where the uptake did not increase significantly, that is, $44.5 \mathrm{mgg}^{-1}$ at $500 \mathrm{mg} \mathrm{L}^{-1}$.

Three theoretical isotherm models, namely, the Langmuir [30], Freundlich [31], and Sips [32], were chosen in this study in order to describe the adsorption process. These adsorption isotherm models are widely used in adsorption study and their applications are discussed in literature [20]. The linearised equations of the models are expressed as follows:

$$
\begin{aligned}
\text { Langmuir: } \frac{C_{e}}{q_{e}} & =\frac{1}{K_{L} q_{m}}+\frac{C_{e}}{q_{m}}, \\
\text { Freundlich: } \ln q_{e} & =\frac{1}{n_{F}} \ln C_{e}+\ln K_{F}, \\
\text { Sips: } \ln \left(\frac{q_{e}}{q_{m}-q_{e}}\right) & =K_{L F} \ln C_{e}+\ln K_{S},
\end{aligned}
$$

where $q_{m}\left(\mathrm{mg} \mathrm{g}^{-1}\right)$ is the maximum monolayer adsorption capacity, $K_{L}\left(\mathrm{~L} \mathrm{mg}^{-1}\right)$ is the Langmuir constant, $K_{F}\left(\mathrm{mg} \mathrm{g}^{-1}\right.$ $\left.\left(\mathrm{L} \mathrm{mg}^{-1}\right)^{1 / n}\right)$ is the adsorption capacity of the adsorbent, 
TABLE 3: Calculated parameters and error functions for the Langmuir, Freundlich and Sips models.

\begin{tabular}{|c|c|c|c|c|c|}
\hline \multicolumn{2}{|c|}{ Langmuir } & \multicolumn{2}{|c|}{ Freundlich } & \multicolumn{2}{|c|}{ Sips } \\
\hline$q_{m}\left(\mathrm{mgg}^{-1}\right)$ & 49.529 & $K_{F}\left[\mathrm{mgg}^{-1}\left(\mathrm{~L} \mathrm{mg}^{-1}\right)^{1 / n}\right]$ & 4.087 & $q_{m}\left(\mathrm{mgg}^{-1}\right)$ & 60.700 \\
\hline$K_{L}$ & 0.033 & $n_{F}$ & 2.212 & $K_{s}\left(\mathrm{~L} \mathrm{mg}^{-1}\right)$ & 0.038 \\
\hline$R_{L}$ & 0.057 & & & $K_{L F}$ & 1.253 \\
\hline$R^{2}$ & 0.993 & $R^{2}$ & 0.900 & $R^{2}$ & 0.951 \\
\hline$\chi^{2}$ & 1.624 & $\chi^{2}$ & 12.741 & $\chi^{2}$ & 2.328 \\
\hline EABS & 18.352 & EABS & 49.706 & EABS & 21.314 \\
\hline
\end{tabular}

$n_{F}$ value (between 1 and 10) indicates favourability of the adsorption process, $K_{S}\left(\mathrm{Lg}^{-1}\right)$ is Sips constant, and $K_{L F}$ is the exponent.

Separation factor $\left(R_{L}\right)$ can be calculated from Langmuir constant and it is used to predict the favourability of the adsorption process [33]

$$
R_{L}=\frac{1}{\left(1+K_{L} C_{i}\right)},
$$

where $R_{L}=0$, unfavourable when $R_{L}>1$, linear when $R_{L}=$ 1 , and favourable when $0<R_{L}<1$ [34].

The Langmuir, Freundlich, and Sips models were compared using their $R^{2}$, EABS, and $\chi^{2}$ values in order to determine the best model to describe the adsorption process. From Table 3, all three models displayed high $R^{2}$ values $\left(R^{2}>0.9\right)$ with the Langmuir being the highest followed by Sips and Freundlich models. The Langmuir model also exhibited the lowest EABS and $\chi^{2}$ values among the three models. This indicates that the Langmuir model is the best fitted model to the experimental data which assumes that the RB molecules formed a single layer on the CEC's surface. Both $R_{L}$ and $n_{F}$ values indicate that the adsorption of $\mathrm{RB}$ onto CEC is a favourable process. The maximum monolayer adsorption capacity $\left(q_{m}\right)$ for CEC is determined as $49.5 \mathrm{mg} \mathrm{g}^{-1}$. The performance of CEC in removing $\mathrm{RB}$ is lower than Casuarina equisetifolia needle $\left(82.3 \mathrm{mgg}^{-1}\right)$ [6] and Azolla pinnata (72.2 $\mathrm{mg} \mathrm{g}^{-1}$ ) [27] and higher than jackfruit seed (26.4 $\left.\mathrm{mg} \mathrm{g}^{-1}\right)$ [28], acid treated Acacia nilotica leaf $\left(22.4 \mathrm{mg} \mathrm{g}^{-1}\right)$ [14], and microwave treated Acacia nilotica leave $\left(24.3 \mathrm{mg} \mathrm{g}^{-1}\right)[14]$.

3.6. Regeneration Study. An alternative of disposing or incinerating the used adsorbents, the regeneration of the adsorbents' removal capabilities using chemicals can be investigated as it can reduce disposal problem and save cost from using fresh adsorbents. Distilled water and $0.1 \mathrm{M} \mathrm{NaOH}$ were used to regenerate CEC in this study and the result is shown in Figure 6. Fresh CEC yielded $68.9 \%$ RB removal while distilled water and base by the third cycle only yielded $42.6 \%$ and $11.5 \%$ removal, respectively. Distilled water managed to regenerate around $40 \%$ of CEC's original removing capability which is considerably high for a simple washing solution. Our previous works on the removal of $\mathrm{RB}$ also showed similar result in the regeneration of the adsorbents where base washing tend to result in lower percentage removal on consecutive washing cycle, and this may be due to the removal

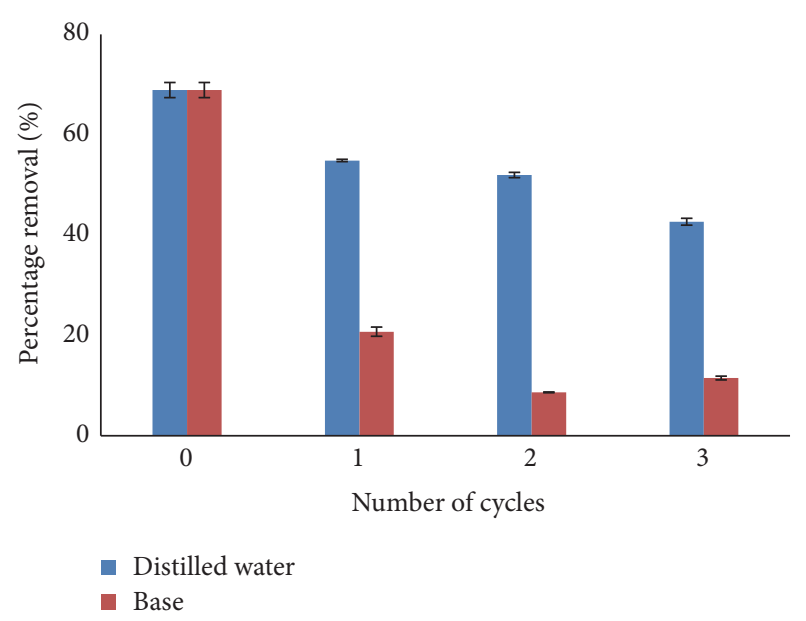

FIGURE 6: The regeneration of CEC using distilled water and $0.1 \mathrm{M}$ $\mathrm{NaOH}$.

of lignin and low molecular weight wax which may interact with the RB dye molecules $[6,28]$.

\section{Conclusion}

CEC has shown to have a good potential as an adsorbent in removing $\mathrm{RB}$ from aqueous solution. It has several advantages where CEC's performance is not severely affected by the change of $\mathrm{pH}$, ionic strength, and temperature making it a very versatile adsorbent. The $\mathrm{pH}$ and ionic strength experiments indicated that the adsorption of RB onto CEC does not depend on electrostatic interactions. The Langmuir model can be used to describe the process where CEC's $q_{m}$ value is $49.5 \mathrm{mg} \mathrm{g}^{-1}$.

\section{Competing Interests}

All authors declare no conflict of interests.

\section{References}

[1] G. De Aragão Umbuzeiro, H. S. Freeman, S. H. Warren et al., "The contribution of azo dyes to the mutagenic activity of the Cristais River," Chemosphere, vol. 60, no. 1, pp. 55-64, 2005.

[2] G. Crini, "Non-conventional low-cost adsorbents for dye removal: a review," Bioresource Technology, vol. 97, no. 9, pp. 1061-1085, 2006. 
[3] M.-H. Wang, J. Li, and Y.-S. Ho, "Research articles published in water resources journals: a bibliometric analysis," Desalination and Water Treatment, vol. 28, no. 1-3, pp. 353-365, 2011.

[4] C. Orwa, A. Mutua, R. Kindt, R. Jamnadass, and S. Anthony, "Casuarina equisetifolia," http://www.worldagroforestry.org/ treedb2/AFTPDFS/Casuarina_equisetifolia.PDF.

[5] N. Subbarao and C. Rodriguez-Barrueco, Casuarinas, Science Publishers, LaBombard Road North, Lebanon, 1995.

[6] M. R. R. Kooh, M. K. Dahri, and L. B. L. Lim, "The removal of rhodamine B dye from aqueous solution using Casuarina equisetifolia needles as adsorbent," Cogent Environmental Science, 2016.

[7] M. K. Dahri, M. R. R. Kooh, and L. B. L. Lim, "Removal of methyl violet 2B from aqueous solution using Casuarina equisetifolia needle," ISRN Environmental Chemistry, vol. 2013, Article ID 619819, 8 pages, 2013.

[8] M. K. Dahri, M. R. R. Kooh, and L. B. L. Lim, "Application of Casuarina equisetifolia needle for the removal of methylene blue and malachite green dyes from aqueous solution," Alexandria Engineering Journal, vol. 54, no. 4, pp. 1253-1263, 2015.

[9] A. K. Srivastava and R. S. Ambasht, "Litterfall, decomposition, and nitrogen release in two age groups of trees in Casuarina equisetifolia plantations in the dry tropical Vindhyan plateau, India," Biology and Fertility of Soils, vol. 21, no. 4, pp. 277-283, 1996.

[10] K. Rajendran and P. Devaraj, "Biomass and nutrient distribution and their return of Casuarina equisetifolia inoculated with biofertilizers in farm land," Biomass and Bioenergy, vol. 26, no. 3, pp. 235-249, 2004.

[11] A. Abdolali, W. S. Guo, H. H. Ngo, S. S. Chen, N. C. Nguyen, and K. L. Tung, "Typical lignocellulosic wastes and by-products for biosorption process in water and wastewater treatment: a critical review," Bioresource Technology, vol. 160, pp. 57-66, 2014.

[12] T. K. Sen, S. Afroze, and H. M. Ang, "Equilibrium, kinetics and mechanism of removal of methylene blue from aqueous solution by adsorption onto pine cone biomass of Pinus radiata," Water, Air, \& Soil Pollution, vol. 218, no. 1-4, pp. 499-515, 2011.

[13] S. Dawood and T. K. Sen, "Removal of anionic dye Congo red from aqueous solution by raw pine and acid-treated pine cone powder as adsorbent: equilibrium, thermodynamic, kinetics, mechanism and process design," Water Research, vol. 46, no. 6, pp. 1933-1946, 2012.

[14] T. Santhi, A. L. Prasad, and S. Manonmani, "A comparative study of microwave and chemically treated Acacia nilotica leaf as an eco friendly adsorbent for the removal of rhodamine B dye from aqueous solution," Arabian Journal of Chemistry, vol. 7, no. 4, pp. 494-503, 2014.

[15] E. R. Nestmann, G. R. Douglas, T. I. Matula, C. E. Grant, and D. J. Kowbel, "Mutagenic activity of rhodamine dyes and their impurities as detected by mutation induction in Salmonella and DNA damage in Chinese hamster ovary cells," Cancer Research, vol. 39, no. 11, pp. 4412-4417, 1979.

[16] SIGMA-ALDRICH, Rhodamine B [Material Safety Data Sheet] Version 5.4, 2015, http://www.sigmaaldrich.com/MSDS/MSDS/ DisplayMSDSPage.do?country $=$ BN\&language $=$ en \&productNumber $=$ R4127\&brand=SIGMA\&PageToGoToURL=http\%3A\%2F\% 2Fwww.sigmaaldrich.com\%2Fcatalog\%2Fproduct $\% 2$ Fsigma $\%$ 2Fr4127\%3Flang\%3Den.

[17] T. Mahmood, M. T. Saddique, A. Naeem, P. Westerhoff, S. Mustafa, and A. Alum, "Comparison of different methods for the point of zero charge determination of NiO," Industrial \&
Engineering Chemistry Research, vol. 50, no. 17, pp. 10017-10023, 2011.

[18] D. A. Ratkowsky, Handbook of Nonlinear Regression Models, Marcel Dekker, 1990.

[19] Y.-S. Ho, "Selection of optimum sorption isotherm," Carbon, vol. 42, no. 10, pp. 2115-2116, 2004.

[20] K. Y. Foo and B. H. Hameed, "Insights into the modeling of adsorption isotherm systems," Chemical Engineering Journal, vol. 156, no. 1, pp. 2-10, 2010.

[21] M. K. Dahri, M. R. R. Kooh, and L. B. L. Lim, "Water remediation using low cost adsorbent walnut shell for removal of malachite green: equilibrium, kinetics, thermodynamic and regeneration studies," Journal of Environmental Chemical Engineering, vol. 2, no. 3, pp. 1434-1444, 2014.

[22] S. Lagergren, "About the theory of so called adsorption of soluble substances," Kungliga Svenska Vetenskapsakademiens Handlingar, vol. 24, pp. 1-39, 1898.

[23] Y. S. Ho and G. McKay, "Sorption of dye from aqueous solution by peat," Chemical Engineering Journal, vol. 70, no. 2, pp. 115124, 1998.

[24] W. J. Weber and J. C. Morris, "Kinetics of adsorption on carbon from solution," Journal of the Sanitary Engineering Division, vol. 89, no. 2, pp. 31-60, 1963.

[25] B. I. Olu-Owolabi, P. N. Diagboya, and K. O. Adebowale, "Evaluation of pyrene sorption-desorption on tropical soils," Journal of Environmental Management, vol. 137, pp. 1-9, 2014.

[26] H. M. H. Gad and A. A. El-Sayed, "Activated carbon from agricultural by-products for the removal of Rhodamine-B from aqueous solution," Journal of Hazardous Materials, vol. 168, no. 2-3, pp. 1070-1081, 2009.

[27] M. R. R. Kooh, L. B. L. Lim, L. H. Lim, and M. K. Dahri, "Separation of toxic rhodamine B from aqueous solution using an efficient low-cost material, Azolla pinnata, by adsorption method," Environmental Monitoring and Assessment, vol. 188, no. 2, pp. 1-15, 2016.

[28] M. R. R. Kooh, M. K. Dahri, and L. B. Lim, "Jackfruit seed as a sustainable adsorbent for the removal of Rhodamine B dye," Journal of Environment \& Biotechnology Research, vol. 4, pp. 716, 2016.

[29] M. Saif Ur Rehman, M. Munir, M. Ashfaq et al., "Adsorption of Brilliant Green dye from aqueous solution onto red clay," Chemical Engineering Journal, vol. 228, pp. 54-62, 2013.

[30] I. Langmuir, "The adsorption of gases on plane surfaces of glass, mica and platinum," The Journal of the American Chemical Society, vol. 40, no. 9, pp. 1361-1403, 1918.

[31] H. M. F. Freundlich, "Over the adsorption in solution," Journal of Physical Chemistry, vol. 57, pp. 385-470, 1906.

[32] R. Sips, "Combined form of Langmuir and Freundlich equations," The Journal of Chemical Physics, vol. 16, pp. 490-495, 1948.

[33] T. W. Weber and R. K. Chakravorti, "Pore and solid diffusion models for fixed-bed adsorbers," AIChE Journal, vol. 20, no. 2, pp. 228-238, 1974.

[34] G. McKay, H. S. Blair, and J. R. Gardner, "Adsorption of dyes on chitin. I. Equilibrium studies," Journal of Applied Polymer Science, vol. 27, no. 8, pp. 3043-3057, 1982. 

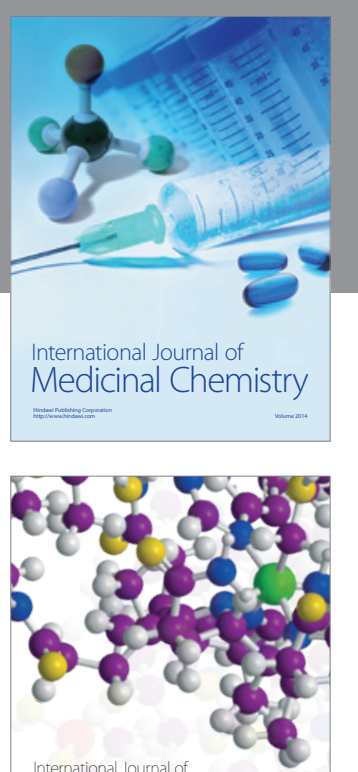

Carbohydrate Chemistry

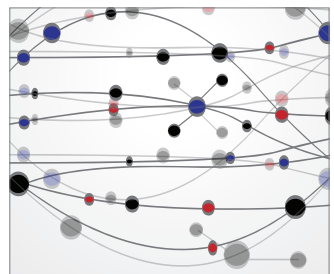

The Scientific World Journal
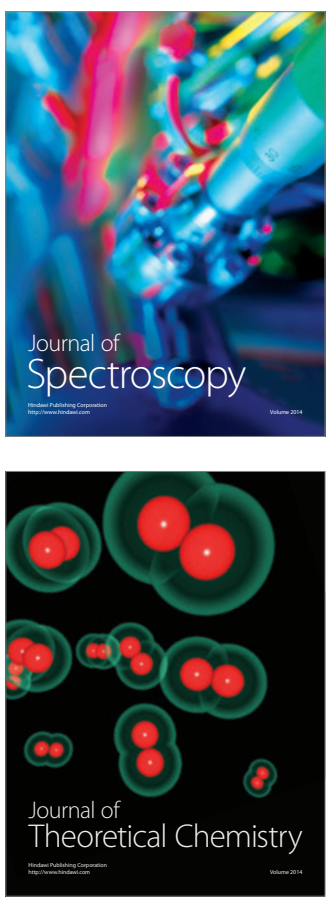
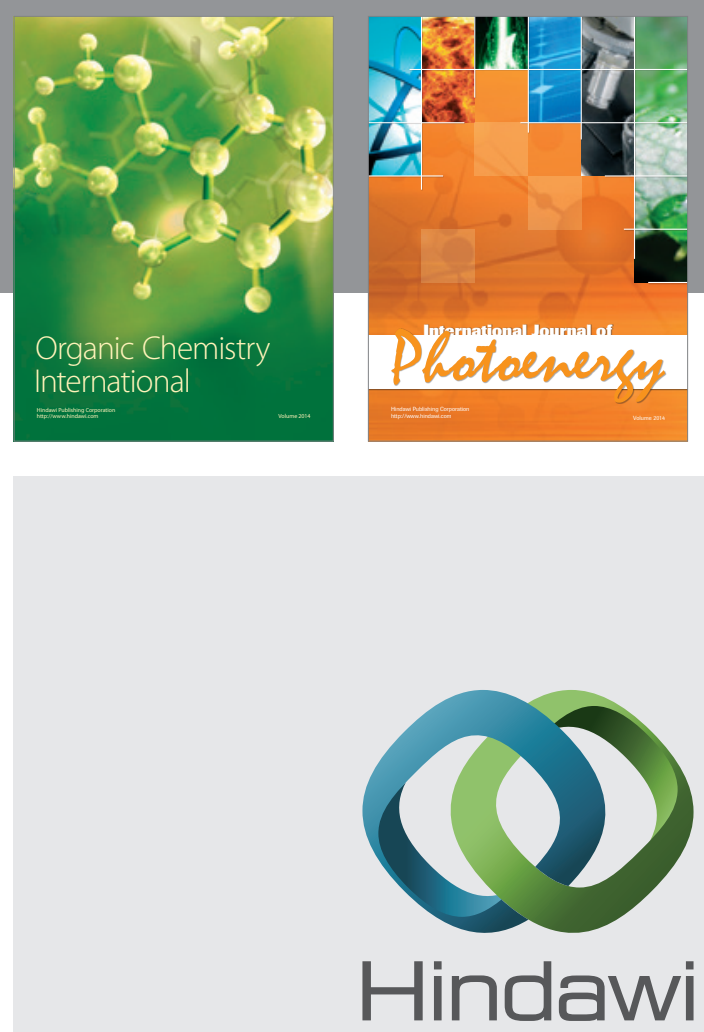

Submit your manuscripts at

http://www.hindawi.com

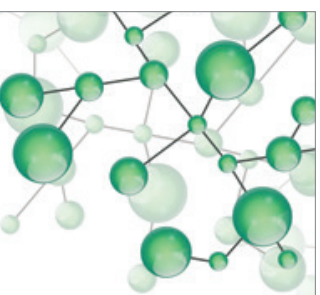

International Journal of

Inorganic Chemistry

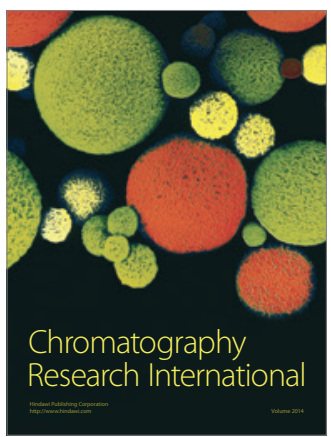

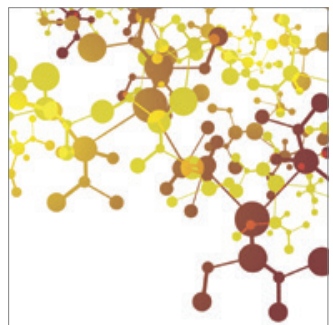

Applied Chemistry
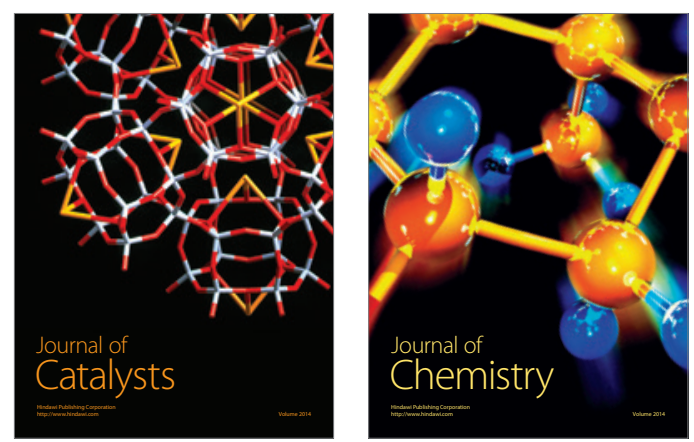
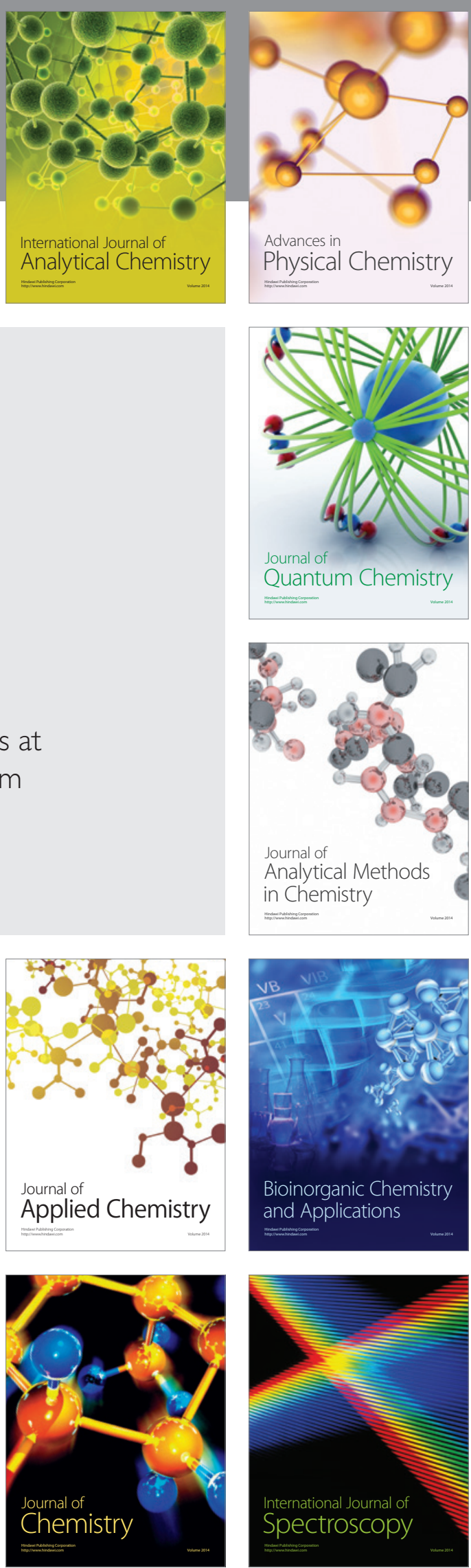